\title{
Influence of Users' Technology Readiness on the Perceived Value of Mobile Phone Enabled Internet Services
}

\author{
A.M.A.S.M. Bandara ${ }^{1 *}$ and L.N.A.C. Jayawardena ${ }^{2}$ \\ Postgraduate Institute of Agriculture \\ University of Peradeniya \\ Sri Lanka
}

\begin{abstract}
The objective of this study was to investigate the influence of users' technology readiness $(T R)$ on the dimensions of perceived value $(P V)$ on mobile phone enabled internet services (MPEIS). Five dimensions of PV, namely utilitarian value, hedonic value uniqueness value, epistemic value, and economic value were considered in this study. A sample of 522 adult mobile phone users were selected covering the Central Province of Sri Lanka using the multistage random sampling. Confirmatory factor analysis was used to validate the measurement model. Covariance based structural equation modelling was used to analyse the structural model. This study revealed that users' TR has a positive influence on the epistemic value of MPEIS, and a negative influence on the economic value of MPEIS. It was also evident that users' TR is not influenced by the utilitarian value, hedonic value and uniqueness value of MPEIS.
\end{abstract}

Keywords: Technology readiness, perceived Value, TRI 2.0, SEM, mobile internet

\section{INTRODUCTION}

The importance of the service industries is growing worldwide and both the industry experts and scholars are interested in developing the knowledge base of service consumers to enable the delivery of services with higher value for the consumer (Yieh et al., 2012). Mobile phones and the mobile services have been revolutionized by the recent developments in the technology. Especially, by the technologies that enabled the transmission of data using a mobile phone (Vriendt et al., 2002). This technological shift was demarcated in the early 1990s with the transformation of mobile communication technologies from analogue to digital. By the year 2003, the mobile phones with accessibility to email services were released to the market. Since then, the mobile technologies have been developed to provide better services in terms of data usage (Lee, 2014). Thus, the mobile phone had transformed into a multi-tasking and multi-purposive device which has provided unlimited growth potentials for the Mobile Service Providers (MSP) (Vriendt et al., 2002).Customers using mobile phones and services have many individual differences. Main objective of this study is to investigate the influence of users' Technology Readiness (TR) on the dimensions of Perceived Value (PV) of mobile phone enabled internet services (MPEIS). The existing literature contains only a limited knowledge about how individuals perceive the technologies in a setting where the use of technology is voluntary and the users are charged for the usage (Wang and $\mathrm{Yu}, 2014$ ). In this

1 Department of Operations Management, Faculty of Management, University of Peradeniya, Sri Lanka

2 Department of Agricultural Extension, Faculty of Agriculture, University of Peradeniya, Sri Lanka

* Corresponding author: amilab@pdn.ac.lk

This is an open-access article distributed under the terms of the Creative Commons Attribution License, which permits unrestricted use, distribution, and reproduction in any medium, provided the original author and source are credited. 
type of a setting PV plays a major role among the many determinants of the usage decisions (Hsu and Lin, 2016).

Despite the multidimensional nature of the PV, a majority of researches have conceptualized it as a single dimension (Al-Debei and Al-Lozi, 2014). There is an inadequacy in the existing knowledgebase to explain the influence of the dimensions of perceived value on the use of technologies in the consumer context (Xu et al., 2015). This study has adopted the five dimensions of PV proposed by Al-Debei and Al-Lozi (2014) in the context of mobile services namely: (1) Utilitarian Value, (2) Hedonic Value, (3) Uniqueness Value, (4) Epistemic Value and (5) Economic Value. Utilitarian Value refers to the extent of effectiveness and efficiency that is perceived by consumers when using information systems (Kim and Han, 2009). Hedonic Value is defined as the level of pleasure and joy users experience when using a certain technology (Al-Debei and Al-Lozi, 2014). Uniqueness Value refers to the sense of differentiation or distinctiveness from others (Tian and McKenzie, 2001). Epistemic Value refers to the knowledge gained upon trying new things (Pihlström and Brush, 2008). Economic Value refers to the gap between value perceived from using mobile internet and the monetary sacrifices (Heinonen and Andersson, 2003). Technology readiness has been defined as "people's propensity to embrace and use new technologies for accomplishing goals in home life and at work". The construct reflects "an overall state of mind resulting from a gestalt of mental enablers and inhibitors that collectively determine a person's predisposition to use new technologies" (Parasuraman, 2000). Parasuraman (2000) has predicted that there can be a relationship between users' TR and PV of MPEIS. This association has not been sufficiently investigated in the existing literature (Yieh et al., 2012). Addressing this knowledge gap five hypotheses were tested in the study. They tested whether the users' technology readiness has a significant influence on the Utilitarian Value of MPEIS $\left(\mathbf{H}_{\mathbf{1}}\right)$, on the Hedonic Value of MPEIS $\left(\mathbf{H}_{2}\right)$, on the Uniqueness Value of MPEIS $\left(\mathbf{H}_{3}\right)$, on the Epistemic Value of MPEIS $\left(\mathbf{H}_{4}\right)$, and on the Economic Value of MPEIS ( $\left.\mathbf{H}_{5}\right)$.

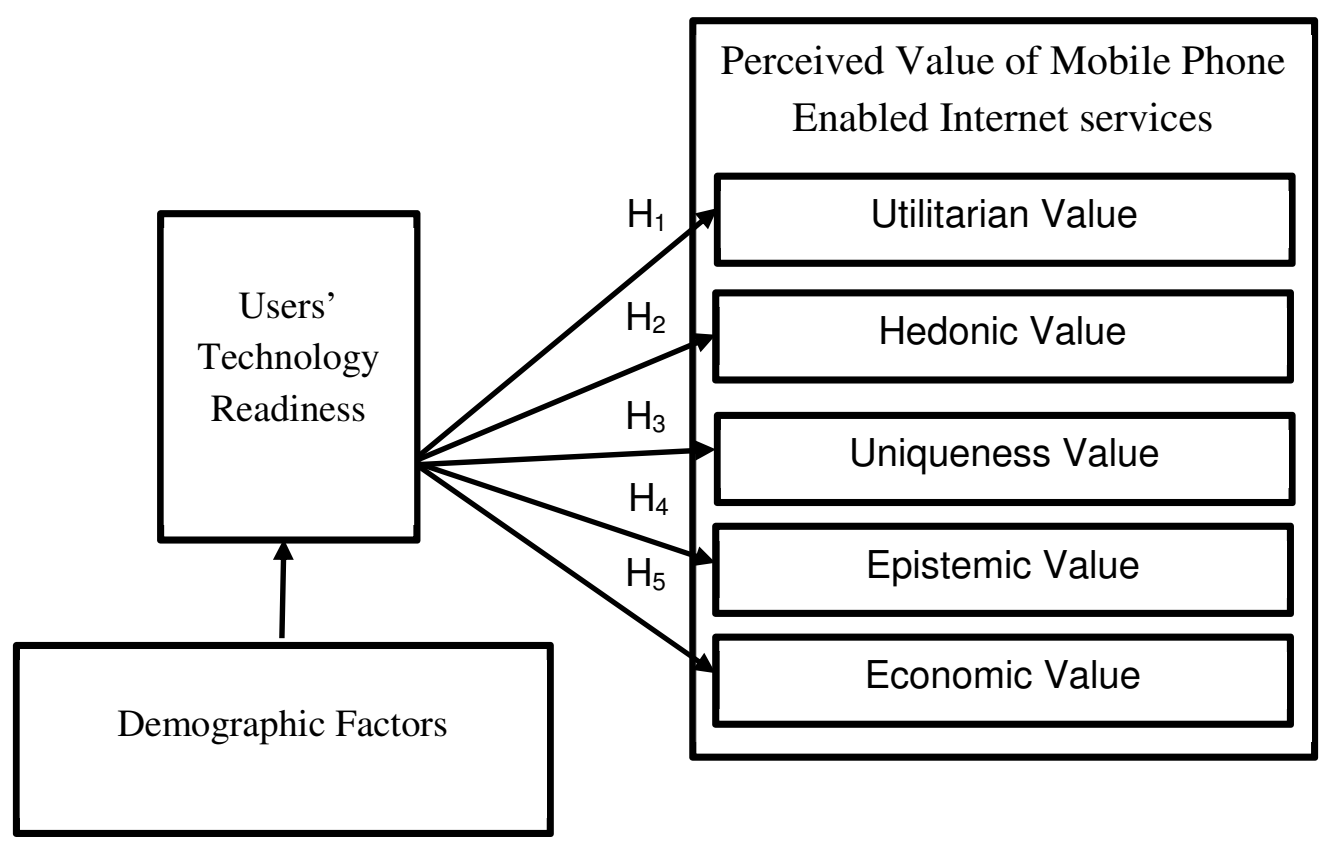

Figure 1. Conceptual Framework. 
Conceptual framework of the study is depicted in figure 1 above. The relationship between users' technology readiness with the PV of mobile phone enabled interned services was examined in the study. The MPEIS was analysed in five dimensions. The impact of demographic factors has not been examined in the context of this study.

\section{METHODOLOGY}

The population of the study was adult (above 18 years) mobile phone users of the Central Province of Sri Lanka. Central Province was selected due to two reasons: (1) the mobile phone penetration rate of the province was the closest value to the mean penetration value of the country and it represented the median value among the other provinces and, (2) the residents' profile of the province was represented by all the major groups of the population (Central Bank of Sri Lanka, 2015).

Obtaining the sample frame for this study was restrained due to the regulations of the mobile telecommunication industry. Therefore, a multistage random sampling approach based on the administration units of the Central Province was employed to derive a representative sample for the study. Administratively, Central province is divided in to three districts: Kandy, Matale and Nuwara Eliya. Each district is divided in to a number of Divisional Secretariat Divisions and in the lowest level, the province is divided into a total of 2,224 Gramaniladhari Divisions (GND). Two stages of the sampling strategy and their justifications are presented below.

\section{Stage 1}

As the initial stage of the sampling process, each district was assigned a quota of GNDs proportionate to the adult population of each district (Table 1). Due to the cost and time constraints, data collection was conducted only in 55 randomly selected GNDs.

Table 1. Adult population and GNDs selected per district

\begin{tabular}{lcc}
\hline District & Adult Population & Number of GNDs \\
\hline Kandy & 999,313 & 30 \\
Matale & 352,437 & 10 \\
Nuwara Eliya & 502,818 & 15 \\
Total & $1,351,750$ & 55 \\
\hline
\end{tabular}

\section{Stage 2}

In stage 2 of the sampling process, 10 respondents were identified from each selected GND using purposive sampling technique. This technique was adopted due to the non-availability of the sampling frame at the GND level as well. The final sample would still be a representative sample of the province since the survey was carried within the representative sample of GNDs selected under Phase1. The sample of 550 mobile phone users was in line with the guidelines given by Krejcie and Morgan (1970). They have indicated that, for populations above the size of $1,000,000$, sample should consist of at least 384 units when a confidence level of $95 \%$ with a margin of error of $5 \%$ is considered. Moreover, this satisfies the requirements of Covariance Based Structural Equation Modelling (Hair et al., 2011). After removing the incomplete 
responses, 522 responses were available for the analysis, which included 258 responses from males and 264 responses from females. The education profile of the respondents revealed that 371 respondents have at least passed GCE Advanced Level examination, while 22 respondents indicated to have educational qualifications below GCE Ordinary Level. The employment profile of the sample revealed that 109 of the respondents were unemployed, 34 of the respondents were self-employed, and the remaining respondents were employed during the time of data collection.

\section{Measurement of variables}

Users' TR has been measured using "The Technology Readiness Index 2.0" (TRI 2.0) which was developed by Parasuraman and Colby (2014). Since this scale is copyrighted by A. Parasuraman and Rockbridge Associates, written permission was obtained from the authors to use the measurement in this study. The scale used four dimensions namely: (1) Optimism, (2) Innovativeness, (3) Discomfort and (4) Insecurity. As per the guidelines from the authors, the items under insecurity and discomfort dimensions were reverse coded since they represent negative themes. Thereafter, TR was calculated by averaging the scores obtained for the four dimensions (i.e. innovativeness, optimism, insecurity and discomfort). The scale developed by Al-Debei and Al-Lozi (2014) was adopted to operationalise the five dimensions of PV. The measurement scale contained three or more items for each dimension and each item was measured by a 5 point Likert scale.

This study investigated the causal relations between a set of variables. The commonly used analytical techniques to investigate causation can be identified as factor analysis, path analysis, structural equation modelling and regression (Sekaran and Bougie, 2013). Structural Equation Modelling (SEM) was employed as the main data analysis technique for the study. The interrelationships among multiple variables were evaluated through regression analyses (Henseler et al., 2016). Literature provide guidelines to select the most appropriate technique between variance and covariance based SEM techniques. In a situation where the objective of the study is to test and confirm an existing theory, covariance based SEM (CB-SEM) would be the appropriate technique. (Hair et al., 2011, 2012, 2013, 2014). Since this study focuses on theory testing, the CB-SEM has been selected as the appropriate analysis technique. AMOS version 23 has been used for CB-SEM analysis. Questionnaires were distributed to a sample of 30 mobile phone users in the same province and the data were analysed to determine the reliability of the items. Results indicated that, Cronbach's Alpha values for all the latent variables were higher than 0.7 indicating a reliable survey instrument. Questionnaire was translated in to Sinhala and Tamil since the majority of the potential respondents were users of native languages. Traditional forward and backward approach has been followed in the translation process (Degroot et al., 1994) to ensure the same meaning in all three languages.

\section{RESULTS AND DISCUSSION}

An Exploratory Factor analysis has been carried out to investigate the item factor loadings. The Principle Component Analysis has been used as the extraction method and Varimax has been used as the rotation method. The items UTV4, HV4, UNV1, and EPV4 have been removed from the analysis to ensure the uni-dimensionality due to the lower factor loadings than 0.6 (Ziegler and Hagemann, 2015). The factor loadings of the retained items for further analysis were above 0.7 . 


\section{Confirmatory factor analysis (CFA)}

Prior to testing the inter-relationship among the variables, the unidimensionality, validity, and reliability for each latent variable has been confirmed using CFA. All the latent variables and their measurement items are used in the analysis. The CFA model is presented in Figure 2 and the Table 2 presents the Cronbach's Alpha values, Composite Reliability (CR) values and Average Variance Extracted (AVE) values for each dimension of PV. Normality tests conducted on data revealed that, the univariate and multivariate normality conditions were fulfilled.

Table 2. Results of CFA.

\begin{tabular}{lccc}
\hline Dimension of PV & Cronbach's Alpha & CR & AVE \\
\hline Epistemic & 0.704 & 0.718 & 0.502 \\
Hedonic & 0.822 & 0.830 & 0.619 \\
Utilitarian & 0.872 & 0.872 & 0.694 \\
Uniqueness & 0.729 & 0.819 & 0.604 \\
Economic & 0.820 & 0.839 & 0.641 \\
\hline
\end{tabular}

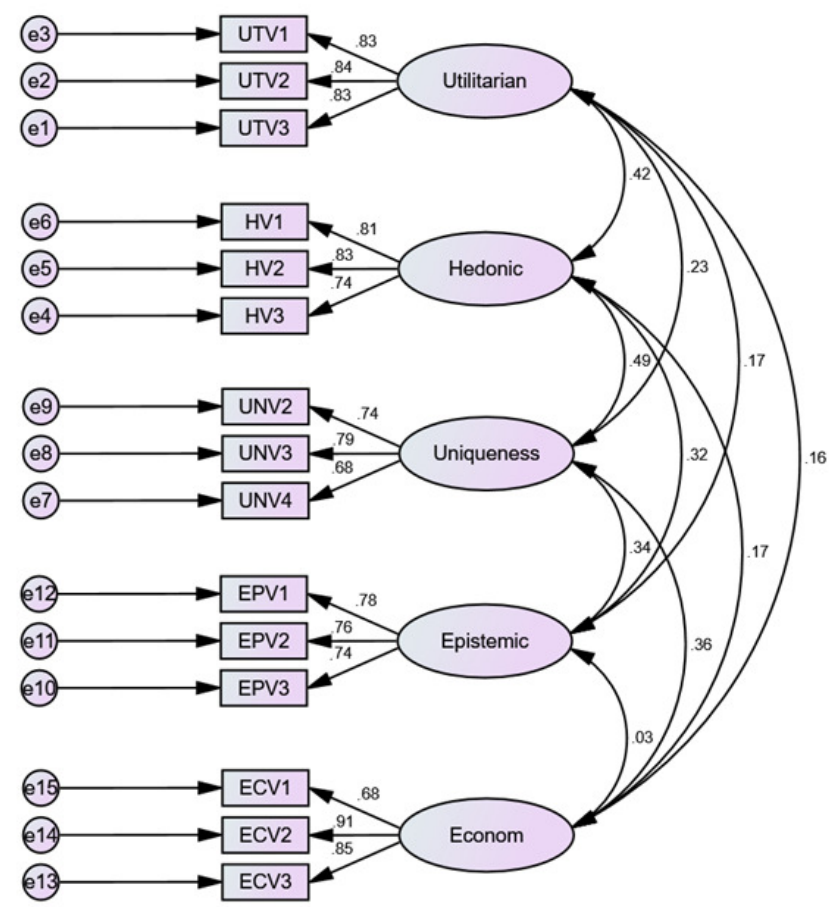

Figure 2. Dimensions of Perceived Value - CFA Model.

Results presented in Figure 2 indicated that the measurement model has achieved Unidimensionality since all the factor loadings were higher than 0.5 (Kose and Demirtasli, 
2012). The lowest factor loading for the model was 0.68. all the AVEs presented in Table 2 were higher than 0.5 indicating an adequate level of convergent validity (Nunnally and Bernstein, 1994).

Table 3. square roots of AVEs and squared correlations between variables.

\begin{tabular}{lccccc}
\hline Dimension of PV & Epistemic & Hedonic & Utilitarian & Uniqueness & economic \\
\hline Epistemic & $\mathbf{0 . 7 0 8 *}$ & & & & \\
Hedonic & 0.323 & $\mathbf{0 . 7 8 7 *}$ & & & \\
Utilitarian & 0.173 & 0.419 & $\mathbf{0 . 8 3 3} *$ & & \\
Uniqueness & 0.336 & 0.491 & 0.228 & $\mathbf{0 . 7 7 7 *}$ & \\
Economic & 0.033 & 0.201 & 0.164 & 0.363 & $\mathbf{0 . 8 0 1 *}$ \\
\hline
\end{tabular}

* Diagonal are square root of AVE and others squared correlation

Discriminant validity of variables is presented in Table 3. Discriminant validity is achieved when the square root of AVEs of each construct are larger than the correlation of the specific construct with any of the other constructs in the model. The square root of AVEs presented as the diagonal items in Table 3 are larger than the squared correlation between constructs presented as off diagonal items indicating an adequate level of Discriminant validity. As indicated in Table 2, Cronbach's Alpha value of each dimension was higher than 0.7 and the $\mathrm{CR}$ value of each dimension was higher than 0.7. Thus, the measurement model indicates an adequate level of internal consistency and reliability (Nunnally and Bernstein, 1994; Hair et al., 2011, 2012, 2013).

Table 4. Model Fit Criteria for CFA Model.

\begin{tabular}{llcc}
\hline $\begin{array}{l}\text { Model Fit } \\
\text { Category }\end{array}$ & \multicolumn{1}{c}{ Index } & $\begin{array}{c}\text { Level of } \\
\text { Acceptance }\end{array}$ & $\begin{array}{c}\text { Value for the } \\
\text { CFA Model }\end{array}$ \\
\hline Absolute fit & $\begin{array}{l}\text { Root Mean Square of Error } \\
\text { Approximation (RMSEA) }\end{array}$ & RMSEA $<0.08$ & 0.047 \\
& Goodness of Fit Index (GFI) & GFI $>0.90$ & 0.953 \\
Incremental fit & Comparative Fit Index (CFI) & CFI $>0.90$ & 0.908 \\
& Tucker-Lewis Index (TLI) & TLI $>0.90$ & 0.926 \\
Parsimonious & Chi Square/Degrees of & Chisq/df $<5.0$ & 1.897 \\
fit & Freedom (Chisq/df) & & \\
\hline
\end{tabular}

Table 4 presented the model fit criteria as per the guidelines of Hu and Bentler (1999). Results indicate that all the values achieved for the CFA model were in the acceptable range. Thus, it can be concluded that the model indicated an adequate level of model fit under all categories.

\section{SEM path model analysis}

Figure 3 presents the path model formulated the study focusing on the research hypotheses. 


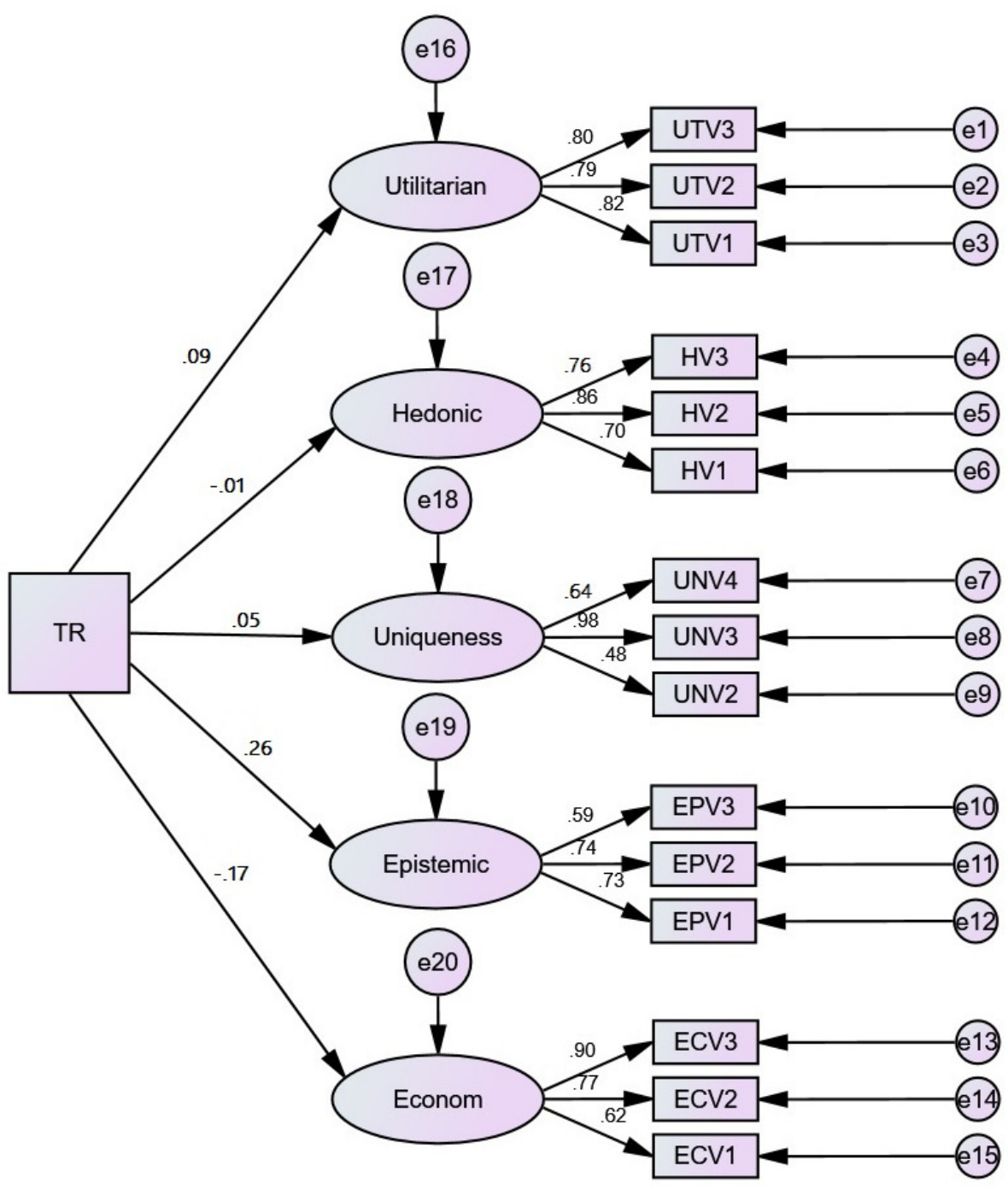

Figure 3. SEM Path Model.

Table 5. Regression Weights and $R^{2}$ Values.

\begin{tabular}{lcccccc}
\hline Path & & $\begin{array}{c}\text { Regression } \\
\text { Weights }\end{array}$ & $\begin{array}{c}\text { Standardized } \\
\text { Regression Weights }\end{array}$ & P & $\mathbf{R}^{\mathbf{2}}$ \\
\hline Utilitarian & $<---$ & TR & 0.162 & 0.088 & 0.151 & 0.05 \\
Hedonic & $<---$ & TR & -0.020 & -0.014 & 0.818 & 0.02 \\
Uniqueness & $<---$ & TR & 0.054 & 0.048 & 0.455 & 0.01 \\
Epistemic & $<---$ & TR & 0.351 & 0.265 & 0.001 & 0.18 \\
Economic & $<---$ & TR & -0.445 & -0.171 & 0.004 & 0.13 \\
\hline
\end{tabular}

The model fit criteria for the SEM path model has indicated acceptable levels of fit criteria $($ RMSEA $=0.067$, GFI $=0.912$, CFI $=0.902$, TLI $=0.914$ and Chisq $/ \mathrm{df}=2.495)$. Table 5 presents the Regression Weights and Standardized Regression Weights for each path and $\mathrm{R}^{2}$ Values for each dimension of PV. 
Results presented in Table 5 revealed that TR has significant impacts only on Epistemic Value $(\mathrm{p}<0.001)$ and Economic Value (p0<.004). Thus, it can be concluded that only the hypotheses $\mathrm{H}_{3}$ and $\mathrm{H}_{4}$ were supported by the study data. Results did not show the evidences to support the hypotheses $\mathrm{H}_{1}, \mathrm{H}_{2}$ and $\mathrm{H}_{3}$. It is evident that the Epistemic Value has positively influenced by TR. There $18 \%$ of the variability of Epistemic Value has been explained by the variability of TR. The Economic Value was negatively influenced by TR, where $13 \%$ of the variability of Economic Value has been explained by the variability of TR

\section{CONCLUSIONS}

Study has investigated the influences of TR on the dimensions of PV. It was found that users' TR has a significant positive influence on the Epistemic Value of MPEIS. In other words, users' TR has a positive influence on the knowledge gained through trying new things. It can be concluded that, higher the users' TR, higher is the knowledge gained from trying new things. It was also found that users' TR has a negative impact on Economic Value of MPEIS. In other words, users TR has a negative influence on the gap between the value perceived from using mobile internet and the monetary sacrifices. It can be concluded that, higher the TR possessed by a user, lessor is the gap between value perceived from using mobile internet services and the monetary sacrifices. Studies of this nature are rare in the existing literature (Erdoğmuş and Esen, 2011; White et al., 2017). Even the existing few studies have not considered the dimensions of PV used in this study. Thus, evidences cannot be found in the literature to support or contradict these findings. However, the findings needs to be verified with further researches on different technologies and consumer groups. The Mobile Service Providers could use these findings to improved customization of their service packages to achieve higher consumer satisfactions.

\section{REFERENCES}

Al-Debei, M. M., and Al-Lozi, E. (2014). Explaining and predicting the adoption intention of mobile data services: A value-based approach. Computers in Human Behavior. 35, 326-338.

Central Bank of Sri Lanka. (2015). Annual report. Ministry of Finance - Sri Lanka.

Degroot, A. M. B., Dannenburg, L., and Vanhell, J. G. (1994). Forward and Backward Word Translation by Bilinguals. Journal of Memory and Language. 33(5), 600-629.

Erdoğmuş, N., and Esen, M. (2011). An Investigation of the Effects of Technology Readiness on Technology Acceptance in e-HRM. Procedia - Social and Behavioral Sciences. 24, 487495.

Hair, J. F., Ringle, C. M., and Sarstedt, M. (2011). PLS-SEM: Indeed a Silver Bullet. The Journal of Marketing Theory and Practice. 19(2), 139-152.

Hair, J. F., Ringle, C. M., and Sarstedt, M. (2012). “ Partial Least Squares ( PLS ) Path Modeling in Strategic Management Research and Practice ." Long Range Planning, pp.1-2.

Hair, J. F., Ringle, C. M., and Sarstedt, M. (2013). Partial Least Squares Structural Equation Modeling: Rigorous Applications, Better Results and Higher Acceptance. Long Range 
Planning. 46(1-2), 1-12.

Heinonen, K., and Andersson, P. (2003). Swedish mobile market: Consumer perceptions of mobile services. Communications and Strategies. 49, 151-171.

Henseler, J., Hubona, G., and Ray, P. A. (2016). Using PLS path modeling in new technology research: updated guidelines. Industrial Management and Data Systems. 116(1), 2-20.

Hsu, C.-L., and Lin, J. C.-C. (2016). Effect of perceived value and social influences on mobile app stickiness and in-app purchase intention. Technological Forecasting and Social Change. $108,42-53$.

Hu, L. T., and Bentler, P. M. (1999). Cutoff criteria for fit indexes in covariance structure analysis: Conventional criteria versus new alternatives. Structural Equation Modeling. 6(1), $1-55$.

Kim, B., and Han, I. (2009). What drives the adoption of mobile data services? An approach from a value perspective. Journal of Information Technology. 24(1), 35-45.

Kose, I. A., and Demirtasli, N. C. (2012). Comparison of Unidimensional and Multidimensional Models Based on Item Response Theory in Terms of Both Variables of Test Length and Sample Size. Procedia - Social and Behavioral Sciences. 46, 135-140.

Krejcie, R. V, and Morgan, D. W. (1970). Determining Sample Size For Research Activities, Educational And Psychological Measurement. Educational and Psychological Measurement. $30,607-610$.

Lee, S. Y. (2014). Examining the factors that influence early adopters' smartphone adoption: The case of college students. Telematics and Informatics. 31(2), 308-318.

Parasuraman, A. (2000). Technology Readiness Index (Tri): A Multiple-Item Scale to Measure Readiness to Embrace New Technologies. Journal of Service Research. 2(4), 307-320.

Parasuraman, A., and Colby, C. L. (2014). An Updated and Streamlined Technology Readiness Index: TRI 2.0. Journal of Service Research. 18(1), 59-74.

Pihlström, M., and Brush, G. J. (2008). Comparing the perceived value of information and entertainment mobile services. Psychology and Marketing. 25(8), 732-755.

Sarstedt, M., Ringle, C. M., Henseler, J., and Hair, J. F. (2014). On the Emancipation of PLSSEM: A Commentary on Rigdon (2012). Long Range Planning. 47(3), 154-160.

Sekaran, U., and Bougie, R. (2013). Research methods for business. In Research methods for business, pp. 436-450.

Tian, K. T., and McKenzie, K. (2001). The Long-Term Predictive Validity of the Consumers' Need for Uniqueness Scale. Journal of Consumer Psychology. 10(3), 171-193.

Vriendt, J. De, Laine, P., Lerouge, C., and Xu, X. (2002). Mobile network evolution: a revolution on the move. IEEE Communications Magazine, 40(4). 104-111.

Wang, X., and Yu, Y. (2014). How individual characteristics influence people's evaluation towards information technology in different contexts. Behaviour and Information Technology. 
34(3), 286-293.

White, C. J., McMurray, A. J., and Rudito, P. (2017). Human values and technology readiness: the mediating role of consumer perceived value. International Journal of Services Technology and Management. 23(4), 331-347.

Xu, C., Peak, D., and Prybutok, V. (2015). A customer value, satisfaction, and loyalty perspective of mobile application recommendations. Decision Support Systems. 79, 171-183.

Yieh, K., Chen, J., and Wei, M. B. (2012). The Effects of Technology Readiness on Customer Perceived Value: An Empirical Analysis. Journal of Family and Economic Issues. 33(2), 177183.

Ziegler, M., and Hagemann, D. (2015). Testing the Unidimensionality of Items European Journal of Psychological Assessment View project Subclinical Psychopathy in Old Age View project. Article in European Journal of Psychological Assessment. 31(4), 231-237. 